\title{
Internal Medicine Physicians' Financial Relationships with Industry: An Updated National Estimate
}

\author{
Aaron S. Kesselheim, M.D., J.D., M.P.H. ${ }^{\text {}, ~ S t e v e n ~ W o l o s h i n, ~ M . D ., ~ M . S . ~}{ }^{2}$, Zhigang Lu, M.D. ${ }^{7}$,

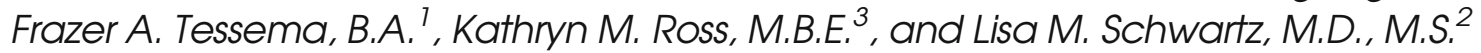 \\ 'Program On Regulation, Therapeutics, And Law (PORTAL), Division of Pharmacoepidemiology and Pharmacoeconomics, Department of \\ Medicine, Brigham and Women's Hospital/Harvard Medical School, Boston, MA, USA; ${ }^{2}$ Center for Medicine and the Media, Dartmouth Institute for \\ Health Policy and Clinical Practice, Lebanon, NH, USA; ${ }^{3}$ American Board of Internal Medicine in Philadelphia, Philadelphia, PA, USA.
}

J Gen Intern Med 34(2):195-7

DOI: $10.1007 / \mathrm{s} 11606-018-4688-\mathrm{Z}$

(c) Society of General Internal Medicine 2018

\section{INTRODUCTION}

Financial relationships between physicians and prescription drug or medical device manufacturers remain controversial. Recent large national studies have shown such relationships are associated with prescription of brand-name drugs, especially those sold by the sponsoring manufacturer, over equally effective lower-cost generics. 1,2

Since 2013, industry payments and gifts are being publicly reported. Also, some large academic medical centers, physician employers, such as Kaiser Permanente, and states have banned or restricted detailing visits, physician payments, or gifts, and some manufacturers have changed their own practices for certain gifts. ${ }^{3}$ We conducted a national survey of internal medicine physicians to assess how their financial relationships with industry have changed in this context.

\section{METHODS}

We randomly sampled 500 clinically active internists and 1000 internal medicine specialists (500 endocrinologists, 500 cardiologists) from the American Board of Internal Medicine's diplomate list; 84 lacked contact information. We asked 10 yes/no questions about "drug, device, or other medically related company" interactions in the last year: food inside or outside the workplace; free drug samples; pens, notepads, Tshirts; honoraria for speaking; payment for consulting services; payment for service on an advisory board; costs of personal expenses for attending meetings; free tickets to events; subsidized admission to meetings; or conferences for which Continuing Medical Education (CME) credits were awarded. To compare ties by physician characteristics, we used Pearson's chi-square test for categorical variables and two-sample $t$ tests for continuous variables. All statistical analyses were performed using SAS 9.4 software (SAS Institute, NC). The Dartmouth College IRB approved the project.

Published online October 5, 2018

\section{RESULTS}

We received 686 surveys (48\% response rate). Respondents averaged 44 years old (SD 8)-13 years (SD 8) out of residency - and were $59 \%$ male, $72 \%$ specialist, and $56 \%$ Caucasian (4\% Hispanic, 34\% Asian, 3\% African-American, and $4 \%$ other). About three-quarters (72\%) reported any financial tie to industry. The most common benefits received were free drug samples (55\%) and food or beverage in $(48 \%)$ and outside $(30 \%)$ the workplace. Fewer physicians reported receiving small gifts $(8 \%)$ or payments for consulting $(4 \%)$ or service on a scientific advisory board (3\%).

In 2017, specialists reported more meals than internists (at work, $61 \%$ for cardiologists and $53 \%$ for endocrinologists vs. $32 \%[p<0.0001]$; outside work, $38 \%$ vs. $13 \%[p<0.001])$ as did male than female physicians (at work, $52 \%$ vs. $43 \%[p=$ $0.03]$; outside work, $34 \%$ vs. $25 \%$ [ $p=0.02]$ ) (Table 1)). Specialists and older physicians generally reported more expertise-related payments (honoraria for speaking, consulting services, scientific advisory boards). These differences were similar to those found in a national physician survey in 2009 with similar questions and response rates. ${ }^{4}$

Compared to 2009, fewer internal medicine physicians reported receiving all types of financial payments, with the greatest decrements related to food/beverage or tickets to sporting or cultural events (75\% vs $42 \%)$ and speakers bureaus/consulting/advisory boards (18\% vs $2 \%$ ) (Table 2 ). Among cardiology specialists, the only significant differences were for drug samples ( $82 \%$ vs $60 \%$ ) and speakers bureaus/ consulting/advisory boards (33\% vs $8 \%$ ).

\section{DISCUSSION}

While financial industry ties have fallen over the past 15 years, a majority of US physicians still reported them in 2017, most prominently, free samples and meals, the latter of which are usually provided during promotional communications related to a brand-name drug or medical device. Free samples are used as a marketing tool ${ }^{5}$ and have been linked to prescribing of high-cost brand-name drugs over lower-cost generic alternatives. $^{6}$ 


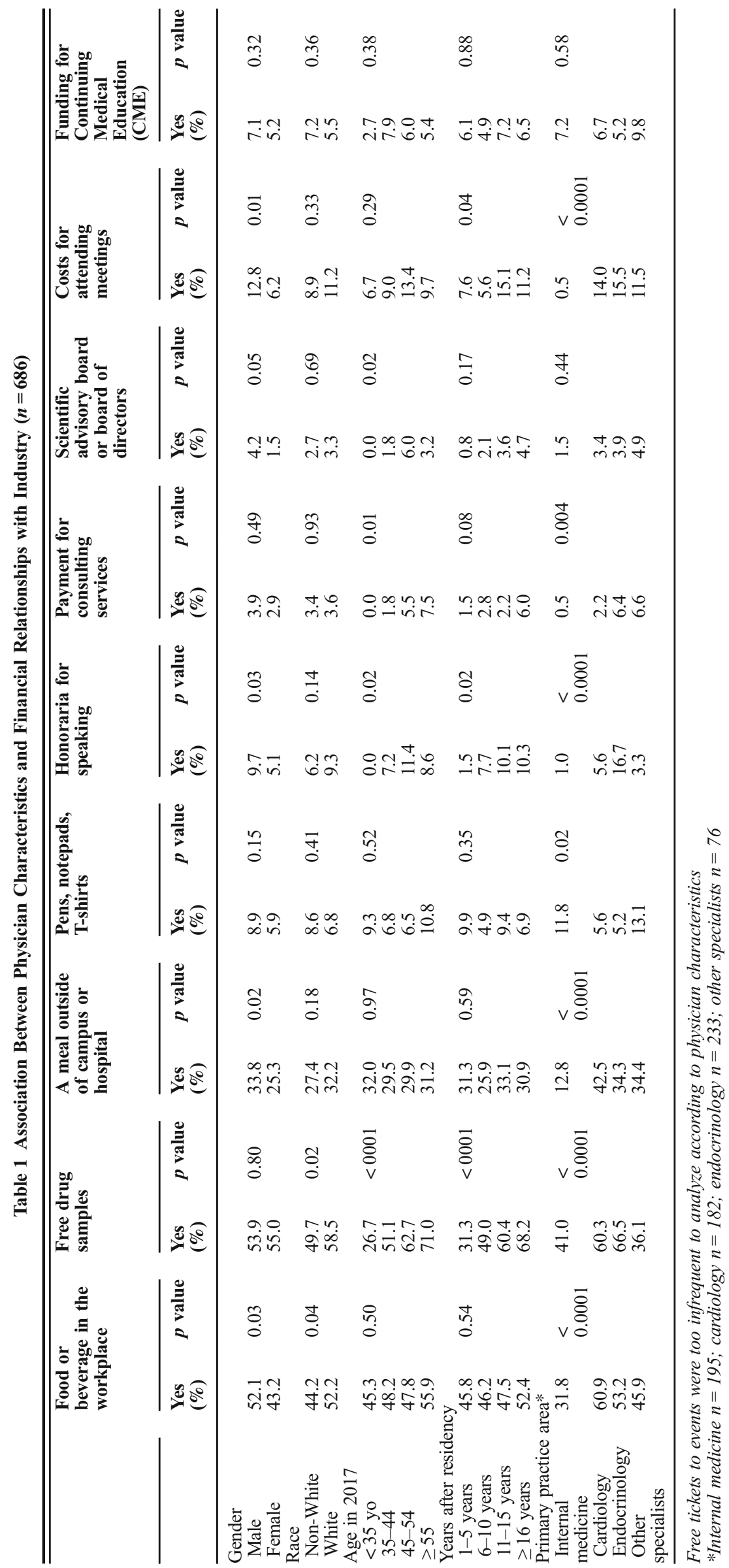


Table 2 Reduction in Internal Medicine and Cardiology Physician Self-Reported Relationships with Industry between 2009 and 2017

\begin{tabular}{|c|c|c|c|c|c|c|c|c|c|c|}
\hline \multirow[b]{2}{*}{ Specialty } & \multirow[b]{2}{*}{ Source } & \multirow[b]{2}{*}{$N$} & \multicolumn{2}{|c|}{ Free drug sample } & \multicolumn{2}{|c|}{$\begin{array}{l}\text { Any food/beverage or } \\
\text { tickets to cultural/ } \\
\text { sporting event }\end{array}$} & \multicolumn{2}{|c|}{$\begin{array}{l}\text { Any meeting expenses } \\
\text { or CME meeting } \\
\text { admissions }\end{array}$} & \multicolumn{2}{|c|}{$\begin{array}{l}\text { Any payment for } \\
\text { speaker's bureau, } \\
\text { consulting, or } \\
\text { advisory board } \\
\text { participant }\end{array}$} \\
\hline & & & Yes $(\%)$ & $p$ value & Yes $(\%)$ & $p$ value & Yes $(\%)$ & $p$ value & Yes $(\%)$ & $p$ value \\
\hline \multicolumn{11}{|c|}{ Internal medicine } \\
\hline & $2009 *$ & 249 & $161(65)$ & $<0.0001$ & $185(75)$ & $<0.0001$ & $53(22)$ & $<0.0001$ & 43 (18) & $<0.0001$ \\
\hline \multirow{3}{*}{ Cardiology } & 2017 & 195 & $80(41)$ & & $82(42)$ & & & & & \\
\hline & 2009 & 218 & $178(82)$ & $<0.0001$ & $165(76)$ & 0.35 & $44(21)$ & 0.77 & $70(33)$ & $<0.0001$ \\
\hline & 2017 & 182 & $108(60)$ & & $128(72)$ & & $34(19)$ & & $14(8)$ & \\
\hline
\end{tabular}

*Source: 2009 represents results reported by Campbell et al. ${ }^{4}$ Data in 2017 rows derived from current survey

Our study is limited by non-response and possible underreporting of ties, as physicians may be reluctant to acknowledge industry ties given heightened scrutiny. The decline in financial ties may reflect successful regulation by states, academic institutions, and large employers, as well as consolidation of more physician practices under these entities, or a consequence of mandatory disclosure under the Sunshine Act. Yet financial connections between physicians and industry remain a prevalent force affecting prescribing practices and health care costs.

Acknowledgements: The authors would like to thank Doris Peter, Ph.D., Yale School of Medicine, for her help in implementing the study.

Corresponding Author: Aaron S. Kesselheim, M.D., J.D., M.P.H.; Program On Regulation, Therapeutics, And Law (PORTAL), Division of Pharmacoepidemiology and Pharmacoeconomics, Department of Medicine, Brigham and Women's Hospital/Harvard Medical School, 1620 Tremont Street Suite 3030, Boston, MA 02120, USA (e-mail: akesselheim@bwh.harvard.edu).

Funding Work at PORTAL on this project was funded by the Laura and John Arnold Foundation. Dr. Kesselheim also receives support from the Harvard Program in Therapeutic Science and the Engelberg Foundation. Survey honoraria and administrative costs were provided by Consumer Union.

\section{Compliance with Ethical Standards:}

The Dartmouth College IRB approved the project.
Conflict of Interest: Drs. Schwartz and Woloshin were co-founders of Informulary, Inc., a company that provides data about the benefits, harms, and uncertainties of prescription drugs, which ceased operations in December 2016. Dr. Kesselheim reports serving as an expert witness for the plaintiffs in the Multidistrict Opiate Litigation on the subject of pharmaceutical marketing. All other authors declare that they do not have a conflict of interest.

\section{REFERENCES}

1. DeJong C, Aguilar T, Tseng CW, Lin GA, Boscardin WJ, Dudley RA. Pharmaceutical industry-sponsored meals and physician prescribing patterns for medicare beneficiaries. JAMA Intern Med 2016;176(8):11141122

2. Fleischman W, Agrawal S, King M, Venkatesh AK, Krumholz HM, McKee D, Brown D, Ross JS. Association between payments from manufacturers of pharmaceuticals to physicians and regional prescribing: cross sectional ecological study. BMJ 2016;354:i4189.

3. Larkin I, Ang D, Avorn J, Kesselheim AS. Restrictions on pharmaceutical detailing reduced off-label prescribing of antidepressants and antipsychotics in children. Health Affairs 2014;33(6):1014-1023.

4. Campbell EG, Rao SR, DesRoches CM, Iezzoni LI, Vogeli C, BolcicJankovic D, Miralles PD. Physician professionalism and changes in physician-industry relationships from 2004 to 2009. Arch Intern Med 2010;170(20):1820-1826

5. Fugh-Berman $\mathbf{A}$ and Ahari $\mathbf{S}$. Following the script: how drug reps make friends and influence doctors. PLoS Medicine 2007;4: e150.

6. Pinckney RG, Helminski AS, Kennedy AG, Maclean CD, Hurowitz L Cote E. The effect of medication samples on self-reported prescribing practices: a statewide, cross-sectional survey. J Gen Int Med 2011:26:40-44. 